\title{
Clinical and Social Status of Patients with Congenital Rubella
}

\author{
SHIRLEY M. GUMPEL \\ From the Department of Microbiology, The Hospital for Sick Children, Great Ormond Street, London
}

\begin{abstract}
Gumpel, S. M. (1972). Archives of Disease in Childhood, 47, 330. Clinical and social status of patients with congenital rubella. Eighty-five older patients with congenital rubella attending The Hospital for Sick Children were reassessed, paying special attention to their development and adaptation to their handicaps.

They were a very handicapped group of children, nearly all were deaf, over twothirds had ocular defects, and over half had cardiac defects. 15 children had a single defect. Abnormal finger patternings were present in $35 \%$, but $21 \%$ of the mothers of these children had similar patterning. Only 9 children attended normal schools, the rest attended partial hearing units of residential schools for the deaf, and 24 children were in residential care for the mentally subnormal. Of the patients who had left school, 3 work in sheltered workshops, and 4 work as unskilled labour. No patient known to have had rubella antibody has lost antibody and there was no loss of immunological competence.
\end{abstract}

In the past 30 years rubella has been clearly identified as a cause of fetal damage. Much information has been collected on the progress of the severely handicapped child up to school age (Sheridan, 1964), but less is known about his further prospects, and of the children with less severe handicaps.

Since 1962 the staff of the Department of Microbiology have made a special study of the relation between infection in pregnancy and congenital defects, and in particular into the effect of rubella as a cause of fetal damage. As part of this study, it was felt that all the patients seen and closely studied during their earlier years should be reassessed, paying special attention to their development and adaptation to their handicaps, together with their antibody and immunological status.

Among the important recent work on rubella, two aspects were particularly relevant to this study: firstly, the work of Menser, Dods, and Harley (1967) from Sydney, where they reported a 25-year follow-up of a group of patients with congenital rubella, and showed that many of these patients had become well adjusted despite severe handicaps; and secondly, the work of Kenrick et al. (1968) and Hardy et al. (1969) in which a few patients with

Received 15 October 1971. congenital rubella had no detectable rubella antibody.

In various studies it has been suggested that environmental teratogens could affect dermatoglyphs (Achs, Harper, and Siegel, 1966) and that dermatoglyphs may serve as a marker of a deleterious intrauterine experience (Alter and Schulenberg, 1966). It was felt that in this group of patients with a known deleterious intrauterine experience, it would be useful to record the dermatoglyphs. Finger patterns were chosen as the factor to record, because it would be possible to compare our results with the data supplied by Purvis-Smith and Menser (1968).

\section{Study Population}

All patients who had attended this hospital suspected of having had congenital rubella and living in London or the Home Counties were contacted. The case finding for this survey posed many problems. Before 1961, serological estimations of rubella antibody had not been incorporated in the diagnosis of congenital rubella, and a diagnosis of the rubella syndrome-the term under which it was coded-was made on clinical grounds, supported where possible by a history of maternal rubella during the pregnancy. It was felt that before 1964 patients with congenital rubella might not have been coded as such; therefore an exhaustive search was made through the medical records of all children 
with a combination of the main congenital abnormalities of congenital rubella, namely deafness, cardiac lesions, and cataracts. Congenital rubella was regarded as a likely diagnosis if there was (a) a history of maternal rubella with a rash, or contact with rubella in the first 20 weeks of the pregnancy, and in addition, one or more clinical defects such as deafness, heart disease, or cataract; or (b) if there was no maternal history, but rubella-type defects, including pigmentary retinopathy; or (c) if in the presence of a defect, rubella antibody was present under 4 years of age.

Of 119 patients identified, it was possible to see and investigate 85 of them.

\section{Clinical Examination}

A history was taken of the pregnancy and delivery, development in infancy, present health and schooling of the child, and also the timing of help sought for the individual handicaps of the child, and starting of therapy. Each child had a detailed clinical examination, including tests for vision, hearing, and motor co-ordination. A chest $x$-ray and ECG were included where necessary. A record of finger patterning was included of as many children and mothers as possible.

A few children now in residential institutions were seen by the Resident Medical Officer. They kindly supplied detailed clinical information and a blood sample for laboratory tests.

\section{Laboratory Investigations}

Blood samples were taken from the mother and child, and rubella antibody status investigated using the haemagglutination-inhibition (HI) test. In 25 patients a previous sample of serum was available, and these, together with the new sera, were tested in series.

\section{Results}

General. Of the 85 patients seen, 83 fulfilled the criteria as previously explained for reaching a retrospective diagnosis of congenital rubella. The ages of the patients ranged from 3 to 19 years, 33 of whom were aged 7 to 9 years (Fig. 1). The increase in numbers over this age period represents the effects of the rubella epidemic of 1961-1962 in Great Britain, and of the improved methods of diagnosis due to the rubella antibody estimations introduced at this time.

Maternal history. A history of rubella in pregnancy was present in 54 cases; the timing of infection ranged from 2 weeks before conception to the 20th week of pregnancy. A history of rubella contact during the pregnancy was reported in 6 cases.

Patients. The frequency of rubella-type abnormalities is shown in Table $I$, and the individual grouping of abnormalities in these patients is shown in Table II. It can be seen that nearly all the

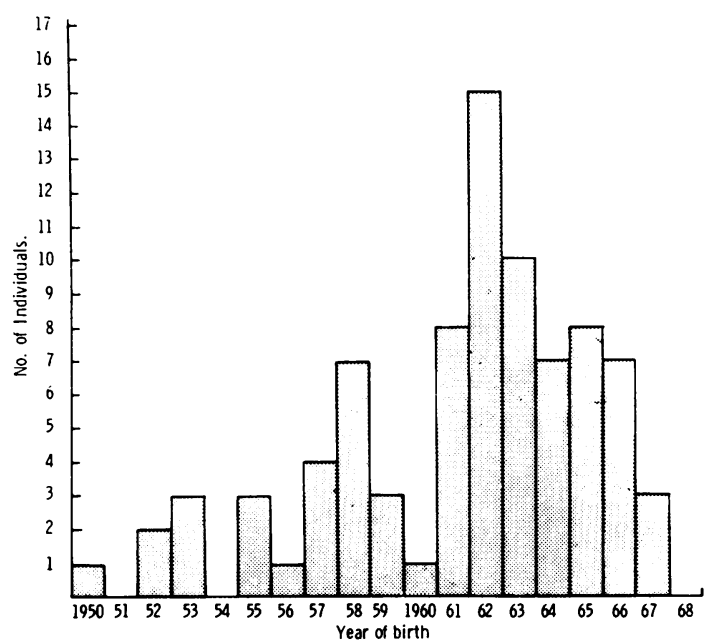

FIG. 1.-Year of birth of children with congenital rubella in the follow-up study.

children were deaf, over two-thirds had ocular defects, and over half had cardiac defects. They were in general a very handicapped group of children. Of 15 children with a single defect, 13 had deafness alone, and 2 older children had congenital heart lesions.

Birthweights. Thirty-two children (44\%) had a birthweight below the 10th centile for weight and maternal gestation (Butler and Alberman, 1969), but this was not a common factor throughout the group as a whole (Fig. 2). There were clear exceptions. Of the children with deafness alone (Fig. 2B), only 2 had a birthweight below the 10 th centile; of those with a heart defect (Fig. 2C), 53\% were below the 10th centile; but it was the multiply-

TABLE I

Frequency of Abnormalities in 83 Children with Congenital Rubella

\begin{tabular}{l|l|l}
\hline \multicolumn{1}{c|}{ Abnormality } & No. & $\%$ \\
\hline Deafness & $74 / 83$ & 89 \\
Cataract & $52 / 83$ & 62 \\
Pigmentary retinopathy & $32 / 52$ & 61 \\
Congenital heart disease & $46 / 83$ & 56 \\
Mental retardation & $32 / 83$ & 39 \\
Cerebral palsies & $15 / 83$ & 17 \\
Low birthwoight at term & $32 / 72$ & 44 \\
Height (<10 centile) & $27 / 70$ & 40 \\
Weight (<10 centile) & $41 / 67$ & 57 \\
Dental defects & $34 / 69$ & 49 \\
Dermatoglyphic abnormalities & $14 / 49$ & 35 \\
Other congenital abnormalities (see & & \\
Table IV) & $26 / 83$ & 29 \\
\end{tabular}



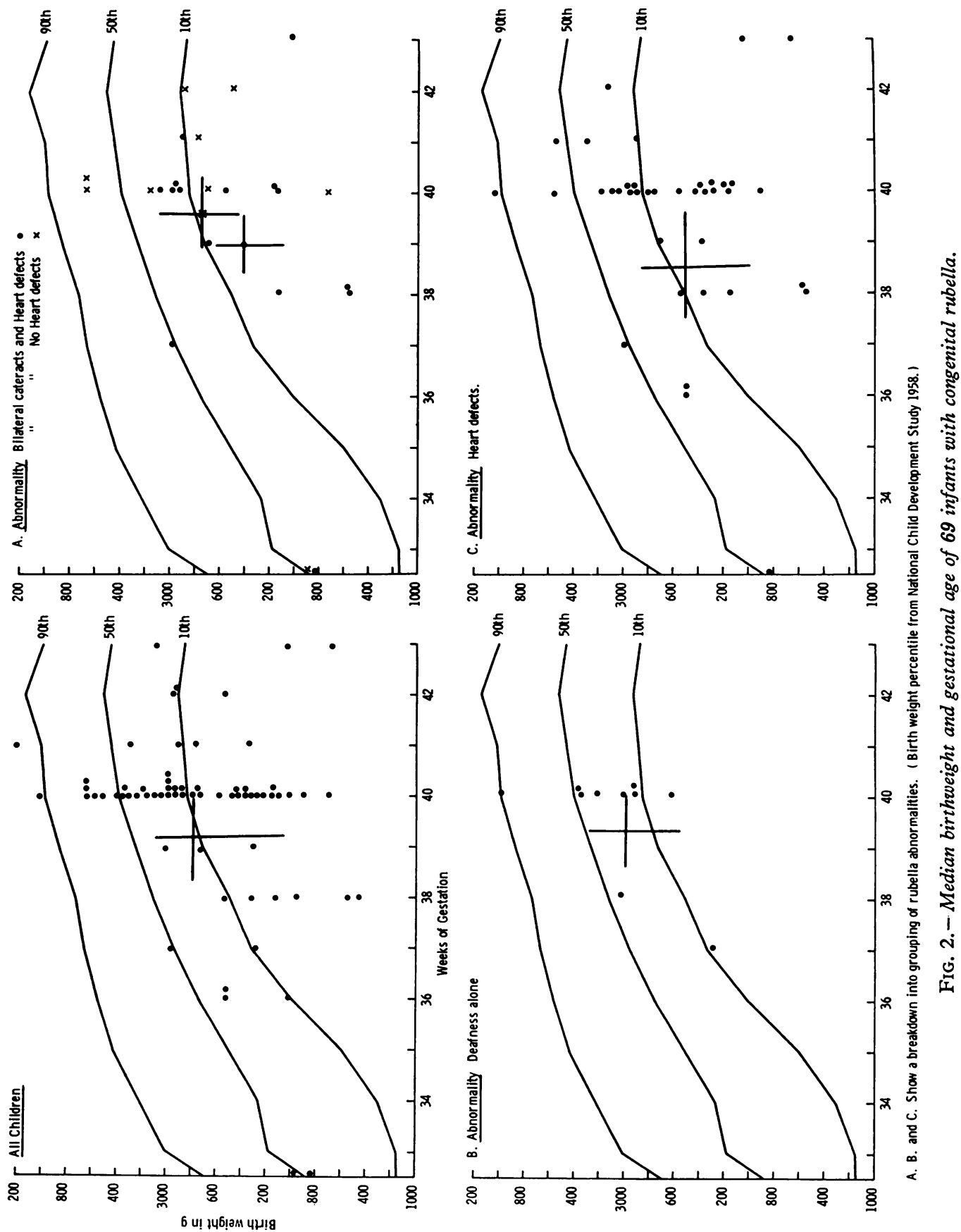

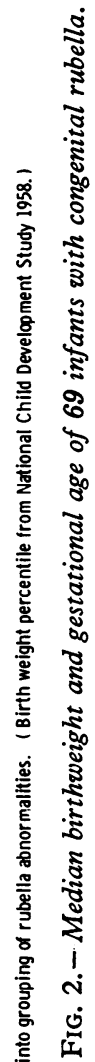


TABLE II

Congenital Abnormalities in 83 Children with Congenital Rubella

\begin{tabular}{|c|c|c|c|c|c|c|c|c|c|}
\hline \multirow[b]{2}{*}{ Rubella Abnormalities } & \multirow{2}{*}{$\begin{array}{c}\text { No. } \\
\text { of } \\
\text { Children }\end{array}$} & \multicolumn{8}{|c|}{ Educational Status of Children } \\
\hline & & $\begin{array}{l}\text { Normal } \\
\text { School }\end{array}$ & $\begin{array}{c}\text { PHU } \\
\text { Normal } \\
\text { School }\end{array}$ & $\begin{array}{c}\text { School } \\
\text { for } \\
\text { Deaf }\end{array}$ & $\begin{array}{l}\text { Multi- } \\
\text { handi- } \\
\text { capped } \\
\text { School }\end{array}$ & $\begin{array}{c}\text { Partially } \\
\text { Sighted } \\
\text { School }\end{array}$ & $\begin{array}{c}\text { Blind } \\
\text { School }\end{array}$ & $\begin{array}{c}\text { Residen- } \\
\text { tial } \\
\text { Institute } \\
\text { for SSN }\end{array}$ & $\begin{array}{c}\text { Not } \\
\text { of } \\
\text { School } \\
\text { Age }\end{array}$ \\
\hline $\begin{array}{l}\text { CHD } \\
\text { Deaf } \\
\text { Deaf, CHD } \\
\text { Deaf, CHD, CP } \\
\text { Deaf (autism) } \\
\text { Deaf, CP } \\
\text { Unilateral cataract } \\
\text { Unilateral cataract CHD } \\
\text { Unilateral cataract, deaf } \\
\text { Unilateral cataract, deaf, CP } \\
\text { Unilateral cataract, deaf, CHD } \\
\text { Unilateral cataract, deaf, CHD, SSN } \\
\text { Unilateral cataract, deaf, CHD, SSN, CP } \\
\text { Unilateral, cataract, deaf, SSN, CP } \\
\text { Bilateral cataract, deaf } \\
\text { Bilateral cataract, deaf, CP } \\
\text { Bilateral cataract, deaf, CHD } \\
\text { Bilateral cataract, deaf, CHD, SSN } \\
\text { Bilateral cataract, deaf, SSN, CP } \\
\text { Bilateral cataract, deaf, SSN } \\
\text { Bilateral cataract, deaf, SSN, CP }\end{array}$ & $\begin{array}{r}2 \\
13 \\
11 \\
3 \\
1 \\
1 \\
1 \\
4 \\
1 \\
1 \\
8 \\
3 \\
1 \\
2 \\
1 \\
1 \\
3 \\
14 \\
3 \\
6 \\
3\end{array}$ & $\begin{array}{l}2 \\
1 \\
1\end{array}$ & $\begin{array}{l}7 \\
5\end{array}$ & $\begin{array}{l}5 \\
4 \\
3 \\
1\end{array}$ & 1 & 1 & 1 & $\begin{array}{l}9 \\
3 \\
4 \\
3\end{array}$ & $\begin{array}{l}1 \\
4 \\
2\end{array}$ \\
\hline Total & 83 & 9 & 16 & 19 & 1 & 1 & 1 & 24 & 11 \\
\hline
\end{tabular}

CHD, congenital heart disease; CP, cerebral palsy; SSN, severely subnormal.

handicapped and most damaged children (Fig. 2A) who had the lowest birthweights for gestational age.

Subsequent progress. In the subsequent general development of these children, only $13(40 \%)$ of the girls and $14(40 \%)$ of the boys were below the 10th centile for height when examined, whereas more children were still below the 10th centile for weight, $18(58 \%)$ of the girls and $23(55 \%)$ of the boys. It was noticeable in this series when examining the children how often they appeared tall, for the majority were above the 10th centile for height and below the 10th centile for weight. Only 3 of the children had the elfin facies described by Dods (1951).

Twins. There were two pairs of twins in this study. One pair was dizygotic and born at the 33rd week of gestation, with birthweights below the 10th centile; in subsequent development only the smaller twin remained below the 10th centile for height and weight. The other pair were nonidentical girls with birthweights below the 10th centile at 38 weeks who have remained small and short for their age.

\section{Specific Defects}

Ocular defects. 54 children had ocular defects.
31 children had bilateral cataracts, 21 had unilateral cataract, and 2 had squints. Pigmentary retinopathy was found in 32 children without bilateral cataracts.

(a) Bilateral cataracts. Only 3 of the 31 children with bilateral cataracts were considered to have any useful vision, the best being $6 / 36$ corrected. These 3 children were also deaf, but they had a normal IQ and were able to function within an educational system; 2 were at boarding schools for the deaf, and one at a boarding school for the multiplyhandicapped. Nearly all these children with bilateral cataracts were also severely deaf and were regarded as severely subnormal, though the distinction between hearing loss and intellectual immaturity was often difficult to determine. 20 children with bilateral cataracts had cardiac lesions, and 6 had cerebral palsy.

(b) Unilateral cataract. 21 children had unilateral cataract; pigmentary retinopathy of the rubella type was present in the other eye in 15 patients, and in all 21 there was normal visual acuity. 14 had a significant cardiac lesion; 9 had persistent ductus arteriosus ligated in infancy, 3 had a pulmonary stenosis, and 2 had a ventricular septal defect (VSD). 
Hearing and speech defects. 74 children $(89 \%)$ had defects of hearing and speech. In 46 children problems of communication were associated with ocular defects already mentioned. Deafness without ocular defects occurred in 28 children. Nearly all the 28 children were severely deaf with bilateral hearing loss.

CNS. 15 children had evidence of spasticity ranging from minimal motor dysfunction to gross spastic diplegia. 8 children had severe behaviour disorders; 2 were frankly autistic, withdrawn with no speech, and inconclusive response to sound; both were attending junior training centres. 4 deaf children had marked hyperactivity of early childhood improving with age, and 2 children with unilateral cataract and deafness also had behaviour disorders needing psychiatric treatment.

Cardiovascular system. 59 children had congenital heart lesions, diagnosed at or soon after birth (Table III); 25 had cardiac murmurs, some associated with congenital cardiac failure at birth, of which 13 have subsequently been classified as innocent with no cardiac follow-up required. 30 children with congenital heart disease required surgery: 27 had a persistent ductus arteriosus ligated, 25 in infancy, 2 after the second year of

TABLE III

\section{Congenital Heart Disease in 83 Children with Congenital Rubella}

Suspected Congenital Heart Disease at or Soon After Birth Present in 59 Children

\begin{tabular}{|c|c|c|c|}
\hline Surgery & No. & No Surgery & No. \\
\hline $\begin{array}{l}\text { PDA ligation } \\
\text { Blalock's anastomosis } \\
\text { Mustard procedure } \\
\text { Major reconstructive } \\
\text { surgery }\end{array}$ & $\begin{array}{r}27 \\
1 \\
1 \\
1\end{array}$ & $\begin{array}{l}\text { Cardiac murmur } \\
\text { insignificant } \\
\text { Cardiac murmur } \\
\text { FU required }\end{array}$ & $\begin{array}{l}13 \\
16\end{array}$ \\
\hline Total & 30 & & 29 \\
\hline
\end{tabular}

life; 3 patients required major corrective surgery (Table III), the results of which have been very satisfactory. The children all attend special schools for other handicaps, having no restrictions imposed on their physical activities because of cardiac limitations.

Dental abnormalities. These were present in 34 patients; caries (greater than one would expect from the present population) was present in 18 patients, gross malpositioning occurred in 11 patients, of whom 7 also had carious teeth, and late dentition occurred in 5 patients; 3 had their eruption of milk teeth occurring after the first year of life and 2 had delay in their second dentition.

Other defects. Other defects not usually considered of rubella type occurred in 26 children (Table IV). 8 children had undescended testes and this figure should probably be higher as the information was not available on all children. One child developed a slow onset of hydrocephalus at the age of 10 years, and a Spitz-Holter valve was inserted for aqueduct stenosis.

\section{TABLE IV}

Miscellaneous Defects in Children with Congenital Rubella

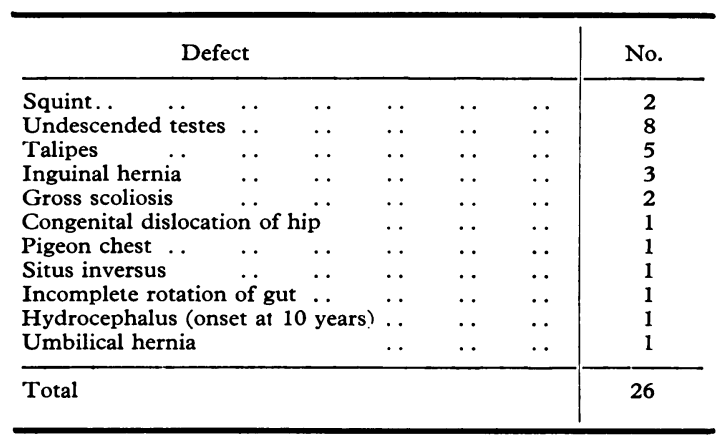

Schooling. The educational status of these children can be seen in Table II. Only 9 children had attended normal schools. 2 of these had isolated cardiac lesions, 4 had cardiac lesions with unilateral cataract, and in 3 the major handicap was deafness. In spite of considerable support by teachers and home environment, 1 deaf child was not managing to keep up in a normal educational setting and was expected to change to special education shortly.

Sixteen children attended Partial Hearing Units (PHU) attached to normal schools. Here the children seemed to have made an excellent adaptation to their handicaps; they were bright, lively children, all with an average or above-average IQ.

Nineteen children attended schools for the deaf, some being only placed in this setting because no PHU was available in their area. 12 of these children had severe deafness and communication problems, with no verbal output.

Twenty-four children were in residential institutions for the subnormal; only 5 of these had useful vision, 4 with unilateral cataract and severe deafness, functioning intellectually as severely 
subnormal, and the other child without an eye defect was frankly autistic. The remaining 19 children were functioning as ineducable blind/deaf children receiving institutional care.

Employment. Seven patients are now at work. 4 had attended secondary modern schools and $3 \mathrm{had}$ attended schools for the deaf. Of the 4 patients who attended secondary modern school, one passed two GCE examinations and is working satisfactorily in an insurance office, 2 are working as general helps in an office and a store, but find the work unstimulating and unsatisfactory. The older boy with minimal sight works at a centre for the disabled. Of the deaf, 2 now work in sheltered workshops and one is a machine operator.

Finger patterning. Investigating the finger patterning of these patients, $14 / 36(38 \%)$ Caucasian children and $4 / 11(36 \%)$ West Indian children with congenital rubella had 8 or more whorls. In the study of patients with congenital rubella by Purvis-Smith and Menser (1968), 28\% had 8 or more whorls, and this compares to the general population where these authors found $7 \%$ could be expected to have this type of finger patterning and in our control series $0 \%$ had this finding (Fig. 3).

The observation was made, however, that in the majority of children with unusual patterning, the mothers also had a similar configuration. In the Caucasian group of mothers and children, 18/24 pairs both had a higher whorl count than is expected in the general population, and $35 \%$ of children and $21 \%$ of mothers had 8 or more whorls, and in the West Indian group 5/6 pairs were unusual.

\section{Laboratory investigations.}

Serology. All 83 children had rubella antibody estimations. Previous samples of sera were retested in parallel in 25 cases. No child previously shown to have antibody had lost antibody. The reciprocal $\mathrm{HI}$ titres ranged from 8 to 1024 and the geometric mean titre (GMT) for children was $76 \cdot 5$. Maternal antibody at the time of the study was present in titres ranging from 16 to 256, the GMT being 107. Serial samples were available on 25 children. There was a fourfold drop in antibody in 5 cases and an eightfold fall in 3 cases over a 4 -year period. 3 children were seronegative on first testing. In 1 of these 3 children, there was a maternal history of a rash just before conception; the child had bilateral cataracts and deafness and is in a residential institution for the subnormal.
The mother had rubella antibody and the child was seronegative when antibody estimates were first made at 5 years of age. In 2 of these children there was a maternal history of contact with rubella at the 2 nd and 3rd weeks of pregnancy

\section{Normal Control Children}
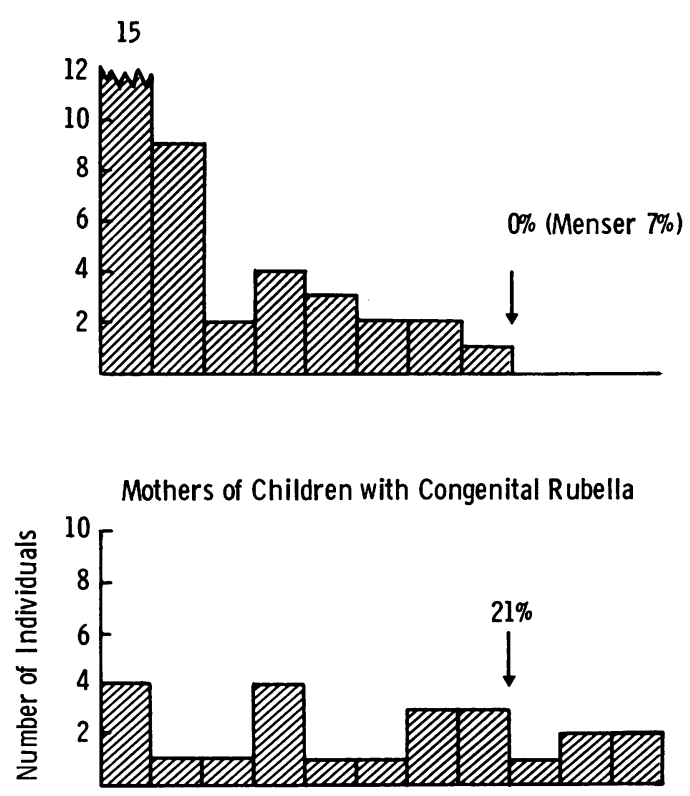

Children with Congenital Rubella

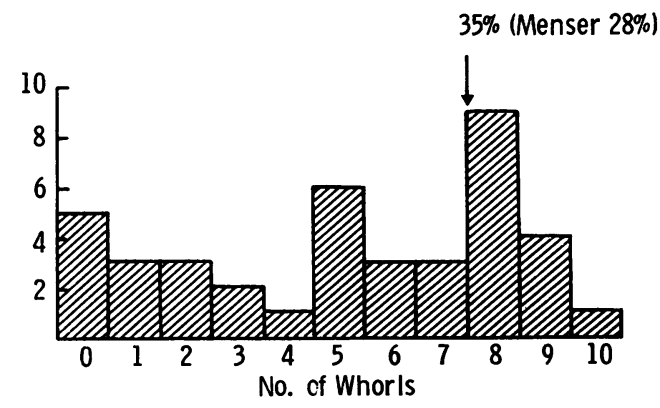

FIG. 3.-Finger patterning of children with congenital rubella/their mothers/controls.

respectively. These children present a problem of diagnosis for they form a small group of children with possible congenital rubella, who lose antibody prematurely. 


\section{Discussion}

These patients with congenital rubella were in general a very handicapped group of children. It is not surprising that most of the children with bilateral cataracts and deafness made very poor adaptations to their handicaps; only 3 of these 31 children are having formal education, 20 of school age are in institutions for the subnormal, and of the children with unilateral cataracts, 4 also are institutionalized. As is well known, the cataracts are just one of multiple ocular derangements in the rubella infected eye, and simple nuclear extraction to remove the cataracts, even if successful, rarely results in an eye capable of vision.

Only 3 of the 31 children with bilateral cataracts had minimal vision preserved; 1 had his operations completed by 1 year and the other 2 by 18 months; 2 have glasses at $6 / 36$ and 1 at $6 / 60$ with $N .18$ for reading.

The children with heart defects had all done well after surgical correction. If surgical intervention was necessary this was usually performed in infancy; after successful correction cardiac abnormalities played little part in school selection or close follow-up.

There were only 13 children with a single defect, of whom 11 had deafness alone, 2 of the deaf children were one each of a pair of twins. Apart from these all but one of the children with deafness alone had a birthweight above $2.8 \mathrm{~kg}$ and all except this child had subsequent heights and weights above the 10th centile. This bears out what has been previously shown (Gumpel, Hayes, and Dudgeon, 1971), that children whose only defect resulting from intrauterine rubella is deafness may have an average birthweight and subsequent normal physical development.

The children who were deaf alone and attended a PHU attached to normal schools were in general doing well, both socially and academically in spite of the fact that their deafness was very severe (in the region of 70-80 decibels loss over the speech range), and that their verbal output was virtually nil. In some of these children the main component in the disability was language disorders, where sounds could be heard but interpretation of sounds was the problem. As to the timing of identification of the deafness, in general the more severely deaf the child, the earlier it was recognized; in general the deafness was noticed by 18 months and help sought. Hearing aids were universally tried, and in approximately half of the children benefit was obtained from them, but this was completely dependent on the supportive help by the mother, health visitors, and peripatetic teachers.
There were examples among these deaf children of possible increasing deafness after infancy, though in this group of patients there was no direct history of a child making meaningful sounds that had ceased with time, but there was reported increasing lack of appreciation of sounds in otherwise bright children. Noticeable benefit was obtained from hearing aids; many mothers described how in spite of there being no verbal output from the child, when the aid was in situ and working the child appeared 'switched on'; without it, they were no longer in communication with their surroundings. This group of children tended to want their aids, and to bring them for repair immediately if they stopped working.

The most important point arising from reexamining these deaf children is to re-emphasize the value of supportive help and follow-through required by the mothers during the child's earliest years. Every conceivable problem will arise in the use of mechanical aids, and failure will result if they are not used properly and at the right time.

The unexpected finding of a similar finger patterning in both mother and child in this group suggests that in future investigations of dermatoglyphs, parental patterning should also be included, particularly before interpretation involving intrauterine insult can be concluded.

Maternal infection occurred from the month before conception in 4 children to the 20th week of the pregnancy. In the 4 children where maternal rubella occurred before conception, 3 had unilateral cataract, deafness, and a heart lesion, and the fourth child had bilateral cataracts and severe deafness requiring institutional care. As has been previously shown (Cooper and Krugman, 1967), the earlier the infection in general the more severe is the abnormality. However, in this group combinations of 3 or 4 major rubella defects occurred after maternal rubella between the 12th and 16th week of the pregnancy, as also reported by Forrest and Menser (1970), and in one child maternal infection was reported to have occurred between the 16th and 20th week and the child had heart disease, bilateral cataracts, deafness, and mental subnormality.

No child previously shown to have rubella antibody had lost antibody. This compares with the findings of Hardy et al. (1969) where 7/20 patients had lost antibody by 4 years of age. 2 of the 4 children with no rubella antibody on first testings over the age of 4 years may well be children with congenital rubella, who have lost antibody. Over the age of 3 to 4 years there was no decline in rubella antibody, in contrast to the finding of 
Menser et al. (1967). The GMT of children with mutiple rubella defects was $1 / 76 \cdot 5$. Similarly, we found no evidence of loss of immunological competence in these children.

The older patients who had made a good adaptation to their handicaps did not wish to be seen for follow-up. Where there was a single handicap of deafness, or deafness with a cardiac lesion or cerebral palsy, there was every reason to believe that the patient would become self-supporting in a sheltered environment, but where there was lack of useful vision and deafness the result was universally unsatisfactory.

I thank Dr. Alistair Dudgeon for his help and encouragement during this study, the physicians of The Hospital for Sick Children for allowing me to see their patients, and the technical staff of the Department of Microbiology for their help and skill with the laboratory investigations. Finally, I express my gratitude to the Joint Research Board of The Hospital for Sick Children for their support of this study.

\section{REFERENCES}

Achs, R., Harper, R. G., and Siegel, M. (1966). Unusual dermatoglyphic findings associated with rubella embryopathy. New England Journal of Medicine, 274, 148.
Alter, M., and Schulenberg, R. (1966). Dermatoglyphics in the rubella syndrome. Fournal of he American Medical Association, $197,685$.

Butler, N. R., and Alberman, E. D. (Editors) (1969). Perinatal Problems: The Second Report of the 1958 British Perinatal Mortality Survey. Livingstone, Edinburgh.

Cooper, L. Z., and Krugman, S. (1967). Clinical manifestations of postnatal and congenital rubella. Archives of Ophthalmology, $77,434$.

Dods, L. (1951). Stillbirths and congenital malformations following rubella and other virus diseases during pregnancy. Modern Trends in Pediatrics, 1st Series, p. 1. Ed. by L. Parsons. Butterworth, London.

Forrest, J. M., and Menser, M. A. (1970). Congenital rubella in schoolchildren and adolescents. Archives of Disease in Childhood, 45, 63.

Gumpel, S. M., Hayes, K., and Dudgeon, J. A. (1971). Congenital perceptive deafness: role of intrauterine rubella. British Medical fournal, 2, 300.

Hardy, J. B., McCracken, G. H., Jr., Gilkeson, M. R., and Sever, J. L. (1969). Adverse fetal outcome following maternal rubella after the first trimester of pregnancy. Fournal of the American Medical Association, 207, 2414.

Kenrick, K. G., Slinn, R. F., Dorman, D. C., and Menser, M. A. (1968). Immunoglobulins and rubella-virus antibodies in adults with congenital rubella. Lancet, 1, 548.

Menser, M. A., Dods, L., and Harley, J. D. (1967). A twenty-fiveyear follow-up of congenital rubella. Lancet, $2,1347$.

Purvis-Smith, S. G., and Menser, M. A. (1968). Dermatoglyphics in adults with congenital rubella. Lancet, $2,141$.

Sheridan, M. D. (1964). Final report of a prospective study of children whose mothers had rubella in early pregnancy. British Medical fournal, 2, 536.

Correspondence to Dr. S. M. Gumpel, Department of Microbiology, The Hospital for Sick Children, Great Ormond Street, London WC1N 3JH. 